\title{
A FUZZY MULTIPLE ATTRIBUTE UTILITY MODEL FOR INTELLIGENT BUILDING ASSESSMENT
}

\author{
Cengiz Kahraman ${ }^{1}$, İhsan Kaya ${ }^{2}$ \\ ${ }^{1}$ Department of Industrial Engineering, İstanbul Technical University, 34367 Maçka, Istanbul, Turkey \\ ${ }^{2}$ Department of Industrial Engineering, Ylldız Technical University, 34349 Ylldız, İstanbul, Turkey \\ E-mails: ${ }^{2}$ ihkaya@yildiz.edu.tr; iekaya@yahoo.com (corresponding author) \\ Received 17 Feb. 2011; accepted 17 Mar. 2011
}

\begin{abstract}
Multi-Attribute Utility Theory (MAUT) is an evaluation scheme which is very popular by decision makers for evaluating their judgments. According to MAUT, the overall evaluation $\mathrm{U}(x)$ of an object $x$ is defined as a weighted addition of its evaluation with respect to its relevant value dimensions. The recent years have witnessed a huge concentration and interest in intelligent buildings' performance that is increasingly evidenced in building design and construction. Intelligent buildings (IBs) are also under assessment according to their IB related characteristics and actual circumstances. For this aim, in this paper a fuzzy multiple attribute utility model for intelligent building assessment is proposed and three alternative intelligent buildings for a business center in Istanbul are evaluated.
\end{abstract}

Keywords: Multiple attribute, utility model, fuzzy, decision making, intelligent building, assessment.

\section{Introduction}

The word "intelligent" was first used to describe buildings in the United States at the beginning of the 1980s. The concept of "intelligent building" was stimulated by the development of information technology and increasingly sophisticated demand for "comfort living environment and requirement for increased occupant control of their local environments" (Wong et al. 2005). The definition of intelligent building (IB) has been evolving with different emphasis, mainly driven by the development of relevant technologies and the changing needs for the built environment. European Intelligent Building Group (EIBG) defines IBs as "Intelligent building is one that incorporates the best available concepts, materials, systems and technologies integrating these to achieve a building which meets or exceeds the performance requirements of the building stakeholders, which include the owners, managers and users, as well as the local and global community". The Intelligent Buildings Institute (IBI) defines IB as "Intelligent building is one that provides a productive and cost-effective environment through optimization of its four basic components - structure, systems, services and management - and the interrelationships between them" (SAVE 2010). IBs should be sustainable, healthy, and technologically aware, meeting the needs of the occupants and business, and should be flexible and adaptable to deal with change (ALwaer, Clements-Croome 2010).

The lifespan of buildings is composed of a series of interlocking processes, starting from initial architectural and structural design, through to actual construction, and then to maintenance and control as well as to eventual demolition or renovation of buildings. Inside this lifespan, essential requirements are generated from considerations of social, environmental, and economic issues for high efficient energy-saving building systems in compliance with building codes and regulations. In this regard, building assessment is becoming popular in order to have a standard method to evaluate new and existing building design. For example, the U.S. Green Building Council developed the Leadership in Energy and Environmental Design Green Building Rating System as a voluntary, consensus based national standard for developing highperformance, sustainable buildings. The Japan Sustainable Building Consortium developed the comprehensive assessment system for building environmental efficiency system as a new environmental assessment system to meet both the political requirements and market needs for achieving a sustainable society. The Building Research Establishment Ltd. (BRE) from UK developed the Building Research Establishment Environmental Assessment Method to assess the environmental performance of both new and existing buildings. Meanwhile, intelligent buildings (IBs) are also under assessment according to their IB related characteristics and actual circumstances. For example, the Asian Institute of Intelligent Buildings developed an IB Index system to specifically assess the performance of IBs; and the BRE developed a matrix tool called MATOOL for assessing the performance of intelligent buildings (Chen et al. 2006).

Decision-making is the process of selecting one or a few alternatives that should be the most favorable one(s) to objective(s). It can also be defined as "Decisionmaking means the selection of the best alternative from numerous alternatives" (Tupenaite et al. 2010). There is a 
considerable amount of scientific literature discussing on decision making problems from different perspectives and it is possible to meet many different techniques to solve these problems. In this paper, one of these techniques Multiple Attribute Utility Theory (MAUT) is used.

The main difference of MAUT from the other multiattribute methods is its usage of utility functions. Utility functions can be applied to transform the raw performance values of the alternatives against diverse criteria, both factual (objective, quantitative) and judgmental (subjective, qualitative), to a common, dimensionless scale. The core of multiattribute utility theory is the use of a pragmatic aggregation function for combining the singleutility functions from each of the system components. The general expression of this aggregation is a multiplicative form. Such forms allow for an interaction or synergy between the components under consideration, just as we desire in the evaluation of security systems.

Keeney and Raiffa (1976) employed the utility concept into complex decision problems involving multiple attributes and multiple conflicting objectives, and provided a systematical approach of multiple attribute utility theory (MAUT) for multicriteria decision making (MCDM) problems. One purpose of the multiple criteria decision making approach is to represent symbolically the decision maker's preferential behavior for a given problem from which the best alternative for implementation can be selected. The set of solutions may consist of many alternatives where each alternative is represented by a set of criteria (attributes) which are conflicting. The decision maker (DM) is faced with the selection of alternatives that are associated with incommensurate and conflicting objectives. MAUT aims to simplify the tasks of verifying assumptions, determining an appropriate mathematical function (the "utility function") to model the DM's preferential behavior, and assessing that function. There are many approaches to describe the decision maker's preferential behavior. Among such methods are those that use mathematical forms to capture and portray the decision maker's preferences and emulate his/her preferential responses to given scenarios. A well-known mathematical form which has been investigated by many researchers is the linear or additive function (Malakooti, Subramanian 1999).

In recent years, some papers have concentrated on the assessment of intelligent buildings. ALwaer and ClementsCroome (2010) used a consensus-based analytical hierarchical process (AHP) model for multi-criteria decisionmaking to identify key issues related to sustainable intelligent buildings. They developed a conceptual model for the selection of the appropriate key performance indicators (KPIs). Wong and Li (2008) proposed a multicriteria decision-making model using the analytic hierarchy process (AHP) approach to evaluate the selection of IB systems. Kolokotsa et al. (2007) proposed a methodology for the buildings' intelligence assessment through the development of a matrix tool. Chen et al. (2006) developed an analytic network process (ANP) based multicriteria decisionmaking model which was called IBAssessor for lifespan energy efficiency assessment of IBs. Hong et al. (2006) presented a Knowledge-oriented Information Visualization
(KIV) approach to facilitate the implementation of building rating systems for the post-assessment of IBs.

Fuzzy sets theory proves very convenient for searching solutions of the problems containing elements of human subjectivity, such as making decisions in order to intelligent building assessment choose construction contractors. Models using fuzzy sets have many advantages. This paper handles the multiattribute utility theory (MAUT) under fuzziness.

The fuzzy set theory is used to represent the linguistic evaluations of decision makers (DMs). In this paper, a fuzzy multiple attribute utility model for intelligent building assessment is proposed and three building alternatives from Istanbul, Turkey are evaluated.

The rest of this paper is organized as follows: Multiple attribute utility models are briefly introduced in Section 2 and a literature review for decision making process by using MAUT is also given in this section. Section 3 includes a fuzzy multiattribute utility model proposal. An application for intelligent building assessment is given in Section 4 . The obtained results and future research directions are indicated in Section 5.

\section{Multiple attribute utility models}

Multiple attribute utility theory (MAUT) was developed by Keeney and Raiffa (1976). One important class of methods in multicriteria decision making (MCDM) is based on constructing a utility or value function $U(x)$, which represents the overall strength of support in favor of the alternative $x$. This approach is known as multiattribute utility theory (MAUT) (Beliakov, Warren 2001). A MAUT analysis of alternatives explicitly identifies the measures that are used to evaluate the alternatives, and helps to identify those alternatives that perform well on a majority of these measures, with a special emphasis on the measures that are considered to be relatively more important (Butler et al. 2001).

In general, the utility $U(x)=U\left(x_{1}, x_{2}, x_{3}, \ldots, x_{n}\right)$, of any combination of outcomes $\left(x_{1}, x_{2}, x_{3}, \ldots, x_{n}\right)$ for $n$ attributes $\left(X_{1}, X_{2}, X_{3}, \ldots, X_{n}\right)$ can be expressed as either $(i)$ an additive or (ii) a multiplicative function. The utility function for each pair of attributes is stated as follow: $U_{1}\left(x_{1}\right), U_{2}\left(x_{2}\right), U_{3}\left(x_{3}\right), \ldots, U_{n}\left(x_{n}\right)$ (Canada, Sullivian 1988).

MAUT is used to assess the decision-makers' preference structure and model it mathematically with a multiple attributes utility function. This multiple attributes utility function is then applied to help the decision maker reach an optimal decision. The usage of MAUT in the literature has been briefly summarized in the following. De Melo Brito et al. (2010) developed several decision models by using different multi-criteria methods. They integrated utility functions with the variable interdependent parameters method to evaluate alternatives through an additive value function regarding mean time to repair, contract cost, and the geographical spread of the candidate's service network, the candidate's reputation and the compatibility of company cultures. Zhang and Xing (2010) presented a fuzzy- 
multi-objective particle swarm optimization (PSO) to solve the fuzzy time-cost-quality tradeoff (TCQT) problem. They described the time, cost and quality as fuzzy numbers and a fuzzy multiattribute utility methodology incorporated with constrained fuzzy arithmetic operations was adopted to evaluate the selected construction methods. They applied PSO to search for the TCQT solutions by incorporating the fuzzy multi-attribute utility methodology. Nishizaki et al. (2010) proposed a method for the sensitivity analysis of multiattribute utility functions in multiplicative form, taking into account the imprecision of the decision maker's judgment in the procedures for determining attribute weights. Streicher-Porte et al. (2009) applied MAUT to the supply of computers to schools in Colombia by evaluating three different supply scenarios. Wang et al. (2009) introduced net promoter score technology to help firms target satisfied or passive consumers, and allow them to highlight the additional value to consumers of environmentallyfriendly products. To achieve the above goals, MAUT was used to develop an aggregated fulfillment level in relation to obtaining such products. Yang et al. (2009) developed a new hybrid methodology to explain the role of Bayesian Networks in MAUT. They proposed a novel utility function, which can appropriately represent the risk results produced and avoid the arguments resulting from exclusive states expressed by linguistic variables with fuzzy nature and the ignorance/incomplete representation of context dependency between decision attributes. Cirtita and Ilieş (2009) proposed a tool to define the best network alternative in downstream supply chain, based on MAUT, creating a value function with scalable importance criteria coefficients. Abouelnaga et al. (2009) used MAUT to optimize the selection process for energy alternatives which are nuclear, hydroelectric, gas/oil, and solar in Egypt. Jiménez et al. (2009) considered the situation where there was the least knowledge of the alternative consequences or performances, i.e. when there is no knowledge whatsoever of the performance of several alternatives for some attributes, i.e. neither a precise performance nor a probability distribution can be specified in MAUT. Zhang (2008) proposed a framework of multi-objective simulation optimization for optimizing equipment-configurations of earthmoving operations by integrating an activity object-oriented simulation, MAUT, a statistical approach like the two-stage ranking and selection procedure and particle swarm optimization algorithm. The MAUT was applied to evaluate the performances generated through simulation by considering multiple criteria and the preference of decision-makers. Kainuma and Tawara (2006) extended the range of the supply chain to include re-use and recycling throughout the life cycle of products and services and proposed the MAUT method for assessing a supply chain. Xu and Huang (2006) proposed a quantitative setup plan evaluation system driven by MAUT coupled with manufacturing error simulation to serve three purposes: $(i)$ to clarify what is optimality of setup plans, (ii) to provide a systematic method of evaluating setup plan alternatives quantitatively, and (iii) to incorporate in existing automatic setup planning systems a hu- man interface to fulfill their potential values. Jiménez et al. (2003) described a decision support system based on an additive or multiplicative multiattribute utility model for identifying the optimal strategy. Butler et al. (2001) described the application and detailed of how they used the simulator, MAUT, and statistical ranking and selection to select the best project configuration of possible configurations. Sohn et al. (2001) proposed a method to aggregate multi-stakeholder opinions and assimilate the public opinions during the course of the decision making process. The analytic hierarchy process (AHP) and MAUT were employed, and for uncertainty analysis, a fuzzy set based approach was adopted in the aggregation phase. Malakooti and Subramanian (1999) developed a generalized decomposable multiattribute utility function for representing the decision maker's preferential behavior. Malakooti (1989) introduced a quasi-concave nonlinear multiple attribute utility function to rank multiple criteria alternatives.

\section{A fuzzy multiatribute utility model}

The fuzzy set theory (FST) was first proposed by Zadeh (1965). FST is a departure from classical two-valued sets, that uses linguistic variables and a continuous range of truth values in the interval $[0,1]$, rather than strict binary (true or false) decisions and assignments. FST has the ability to deal with complex problem, which contain ambiguities. In addition, reasoning with such ambiguous concepts may not be clear and obvious, but rather fuzzy. FST also provides the mathematical tools to handle ambiguous concepts and reasoning, and finally produces crisp answers for these types of problems with subjectivity. Another important aspect of FST is that it uses linguistic variables, thus performing computation with words. If a traditional mathematical approach towards sustainability assessment were adopted, such as cost-benefit analysis or algebraic formulas, then certain factors, which are impossible to quantify, would be left out. There are, however, aspects of sustainability, which cannot be quantified and yet are very important as, for example, values and opinions. In this area of human thought fuzzy logic performs successfully (Zimmermann 1991; Abouelnaga et al. 2009). In this paper, FST is integrated with MAUT and a fuzzy multiple attribute utility model for intelligent building assessment is proposed. The fuzzy MAUT model can be detailed as below.

The fuzzy utility $U(\tilde{x})=U\left(\tilde{x}_{1}, \tilde{x}_{2}, \tilde{x}_{3}, \ldots, \tilde{x}_{n}\right)$ can be expressed as a any combination of outcomes $\left(\tilde{x}_{1}, \tilde{x}_{2}, \tilde{x}_{3}, \ldots, \tilde{x}_{n}\right)$ for $\mathrm{n}$ attributes $\left(\tilde{X}_{1}, \tilde{X}_{2}, \tilde{X}_{3}, \ldots, \tilde{X}_{n}\right)$. The first stage is the determination of the fuzzy scaling factor $\left(\tilde{k}_{i}\right)$. To find the scaling factor $\tilde{k}_{i}$, the following question is asked: "Around what probability $\tilde{P}$ are you indifferent between":

i. The consequence giving a $\tilde{P}$ probability at $\tilde{x}^{*}=\left(\tilde{x}_{1}^{*}, \tilde{x}_{2}^{*}, \tilde{x}_{3}^{*}, \ldots, \tilde{x}_{n}^{*}\right)$ and $(1-\tilde{P})$ probability at $\tilde{x}^{0}=\left(\tilde{x}_{1}^{0}, \tilde{x}_{2}^{0}, \tilde{x}_{3}^{0}, \ldots, \tilde{x}_{n}^{0}\right)$; 

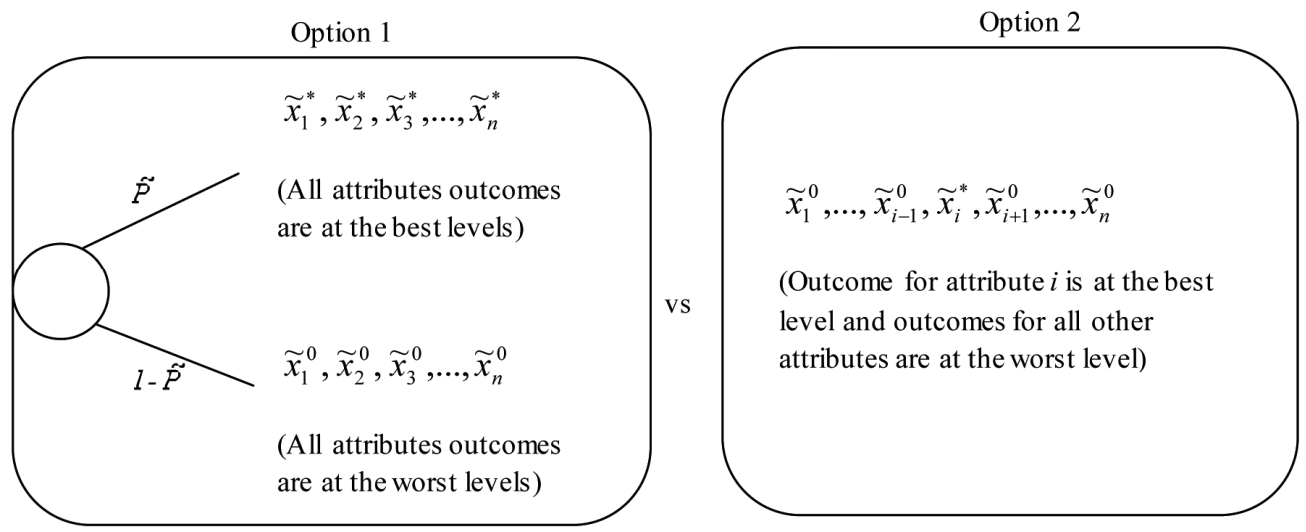

Fig. 1. Illustration of the question to determine the scaling factor $\tilde{k}_{i}$

ii. The consequence $\left(\tilde{x}_{i}^{0}, \ldots, \tilde{x}_{i-1}^{0}, \tilde{x}_{i}^{*}, \tilde{x}_{i+1}^{0}, \ldots, \tilde{x}_{n}^{0}\right)$.

These options are illustrated in Fig. 1 (Canada, Sullivian 1988). The result of such an assessment is that $\tilde{P}=\tilde{k}_{i}$.

To calculate the other scaling factors, the following question is asked successively:

"Select a level of $\tilde{X}_{i}$ (e.g. $\left.\tilde{x}_{\mathrm{i}}^{\prime}\right)$ for attribute $i$ and a level of $\tilde{X}_{j}$ (e.g. $\left.\tilde{x}_{\mathrm{j}}^{\prime}\right)$ for attribute $j$ so that you are indifferent between":

i. An outcome yielding $\tilde{x}_{\mathrm{i}}^{\prime}$ and $\tilde{x}_{j}^{0}$ together, and

ii. An outcome yielding $\tilde{x}_{j}^{\prime}$ and $\tilde{x}_{i}^{0}$ together.

Then Eq. (1) is used to solve for either $\tilde{k}_{i}$ or $\tilde{k}_{j}$, depending on which is unknown:

$$
\tilde{k}_{i} U_{i}\left(\tilde{x}_{i}^{\prime}\right)=\tilde{k}_{j} U_{j}\left(\tilde{x}_{j}^{\prime}\right) .
$$

The rank ordering of the $\tilde{k}_{i}$ 's can be done by asking the decision maker (DM), for instance, whether DM prefers $\left(\tilde{x}_{1}^{*}, \tilde{\bar{x}}_{1}^{0}\right)$ or $\left(\tilde{x}_{2}^{*}, \tilde{\bar{x}}_{2}^{0}\right)$ where $\tilde{\bar{x}}_{1}^{0}$ means all $\tilde{x}$ attributes other than $\tilde{x}_{1}$ are at their respective worst values. If the former is preferred, $\tilde{k}_{1}>\tilde{k}_{2}$, and if the latter is preferred, $\tilde{k}_{2}>\tilde{k}_{1}$.

\subsection{Fuzzy additive utility model}

The condition of applying the additive utility function is that the attributes should be additively independent. This will be true if $\sum_{i=1}^{n} \tilde{k}_{i}=(1,1,1)$ in the model as given in Eq. (2). The utility $U(\tilde{x})$ of any combination of outcomes for $n$ attributes $\left(\tilde{X}_{1}, \tilde{X}_{2}, \tilde{X}_{3}, \ldots, \tilde{X}_{n}\right)$ can be expressed as follows:

$$
U(\tilde{x})=\sum_{i=1}^{n} U\left(\tilde{x}_{i}, \tilde{\bar{x}}_{i}^{0}\right)=\sum_{i=1}^{n} \tilde{k}_{i} U_{i}\left(\tilde{x}_{i}\right),
$$

where $U\left(\tilde{x}_{i}, \tilde{x}_{i}^{0}\right)$ is the fuzzy utility of the outcome for the $i$ th criterion $\tilde{x}_{i}$, and the worst possible outcome for the complement of the ith attribute $\tilde{\bar{x}}_{i}^{0} \cdot U_{i}\left(\tilde{x}_{i}\right)$ is the fuzzy utility of the outcome $\tilde{x}_{i}$ for the $i$ th attribute; $\tilde{k}_{i}$ is the fuzzy weight for the $i$ th attribute and can be defined as:

$$
\tilde{k}_{i}=U\left(\tilde{x}_{i}^{*}, \tilde{\bar{x}}_{i}^{0}\right), \text { for } i=1,2, \ldots, n \text { attributes. }
$$

\subsection{Fuzzy multiplicative utility model}

The utility $U(\tilde{x})$ of any combination of outcomes of $n$ attributes can be obtained from Eq. (4):

$$
\tilde{K} U(\tilde{x})+(1,1,1)=\prod_{i=1}^{n}\left[K \tilde{k}_{i} U_{i}\left(\tilde{x}_{i}\right)+(1,1,1)\right] .
$$

Solving for $U(\tilde{x})$ gives:

$$
U(\tilde{x})=\frac{\prod_{i=1}^{n}\left[\tilde{K} \tilde{k}_{i} U_{i}\left(\tilde{x}_{i}\right)+(1,1,1)\right]-(1,1,1)}{\tilde{K}},
$$

where: $U(\tilde{x})$ is normalized by $U\left(\tilde{x}_{1}^{0}, \tilde{x}_{2}^{0}, \tilde{x}_{3}^{0}, \ldots, \tilde{x}_{n}^{0}\right)=$ $(0,0,0)$ and $U\left(\tilde{x}_{1}^{*}, \tilde{x}_{2}^{*}, \tilde{x}_{3}^{*}, \ldots, \tilde{x}_{n}^{*}\right)=(1,1,1) ; U_{i}\left(\tilde{x}_{i}\right)$ is a conditional utility function of $\tilde{X}_{i}$ normalized by $U_{i}\left(\tilde{x}_{i}^{0}\right)=(0,0,0) \quad$ and $\quad U_{i}\left(\tilde{x}_{i}^{*}\right)=(1,1,1), \quad$ for $i=1,2, \ldots, n ; \tilde{k}_{i}=U\left(\tilde{x}_{i}^{*}, \tilde{\bar{x}}_{i}^{0}\right)$; and $\tilde{K}$ is a scaling constant which provides Eq. (6):

$$
(1,1,1)+\tilde{K}=\prod_{i=1}^{n}\left((1,1,1)+\tilde{K} \tilde{k}_{i}\right)
$$

where: $(-1,-1,-1)<\tilde{K}<(0,0,0)$.

\section{Application}

Istanbul is simultaneously located on the two continents and it is known as a link between east and the west. Istanbul has always been the center of trade and commerce due to its strategic location. The rapid development of the service sector, demand for high-rise office buildings in Istanbul, has led to the completion of many high rises in 
the recent years. Most of these high rises are IBs and all the future high rises are planned to be IBs thereafter. Since the assessment of an IB requires the consideration of many attributes, a fuzzy multiple attribute utility model for intelligent building assessment is proposed for a business center project in this paper. The criteria which are determined from a literature survey (ALwaer, ClementsCroome 2010; Wong, Li 2008; Chen et al. 2006) and decision makers' ideas are used for IBs assessment. These attributes are shown in Table 1.

Table 1. Intelligent building assessment attributes

\begin{tabular}{|c|c|}
\hline $\begin{array}{c}\text { Main } \\
\text { Attributes }\end{array}$ & Sub-Attributes \\
\hline \multirow{7}{*}{$\begin{array}{l}\text { Engineering } \\
\quad \text { (C1) }\end{array}$} & Functionality (C11) \\
\hline & Safety and structure (C12) \\
\hline & Working efficiency (C13) \\
\hline & Responsiveness (C14) \\
\hline & Office automation (C15) \\
\hline & Power supply (C16) \\
\hline & System integration (C17) \\
\hline \multirow{6}{*}{$\begin{array}{l}\text { Environmental } \\
\qquad(\mathrm{C} 2)\end{array}$} & Energy consumption (C21) \\
\hline & Water and Water Conservation (C22) \\
\hline & Materials used, Durability and Waste (C23) \\
\hline & Land use and Site selection (C24) \\
\hline & $\begin{array}{l}\text { Greenhouse Gas Emissions (Pollution) } \\
(\mathrm{C} 25)\end{array}$ \\
\hline & Indoor Environmental Quality (C26) \\
\hline \multirow{3}{*}{$\begin{array}{l}\text { Economical } \\
\quad(\mathrm{C} 3)\end{array}$} & $\begin{array}{l}\text { Economic performance and affordability } \\
\text { (C31) }\end{array}$ \\
\hline & $\begin{array}{l}\text { Initial costs, operating and maintenance } \\
\text { costs (C32) }\end{array}$ \\
\hline & Life cycle costing (C33) \\
\hline \multirow{4}{*}{$\begin{array}{l}\text { Socio-Cultural } \\
\text { (C4) }\end{array}$} & $\begin{array}{l}\text { Functionality, Usability and Aesthetic } \\
\text { aspects (C41) }\end{array}$ \\
\hline & Human comfort (C42) \\
\hline & Health and sanitation (C43) \\
\hline & $\begin{array}{l}\text { Architectural considerations - cultural } \\
\text { heritage integration and the compatibility } \\
\text { with local heritage value (C44) }\end{array}$ \\
\hline \multirow{7}{*}{$\begin{array}{l}\text { Technological } \\
\text { (C5) }\end{array}$} & Work efficiency (C51) \\
\hline & Use of high-tech system (C52) \\
\hline & Use of advanced artificial intelligence (C53) \\
\hline & $\begin{array}{l}\text { Telecom and data system-Connectibility } \\
\text { (C54) }\end{array}$ \\
\hline & $\begin{array}{l}\text { Security monitoring and access control } \\
\text { system (C55) }\end{array}$ \\
\hline & $\begin{array}{l}\text { Addressable fire detection and alarm } \\
\text { system (C56) }\end{array}$ \\
\hline & $\begin{array}{l}\text { Digital addressable lighting control system } \\
\text { (C57) }\end{array}$ \\
\hline
\end{tabular}

Three intelligent building alternatives for a business center project are evaluated with respect to these attributes and the hierarchical structure which is shown in Fig. 2. The building alternatives are coded as IB-A, IB-B, and IB-C, respectively.

The local and global weights and ranks of selection attributes are obtained by using AHP. The obtained results are shown in Table 2.

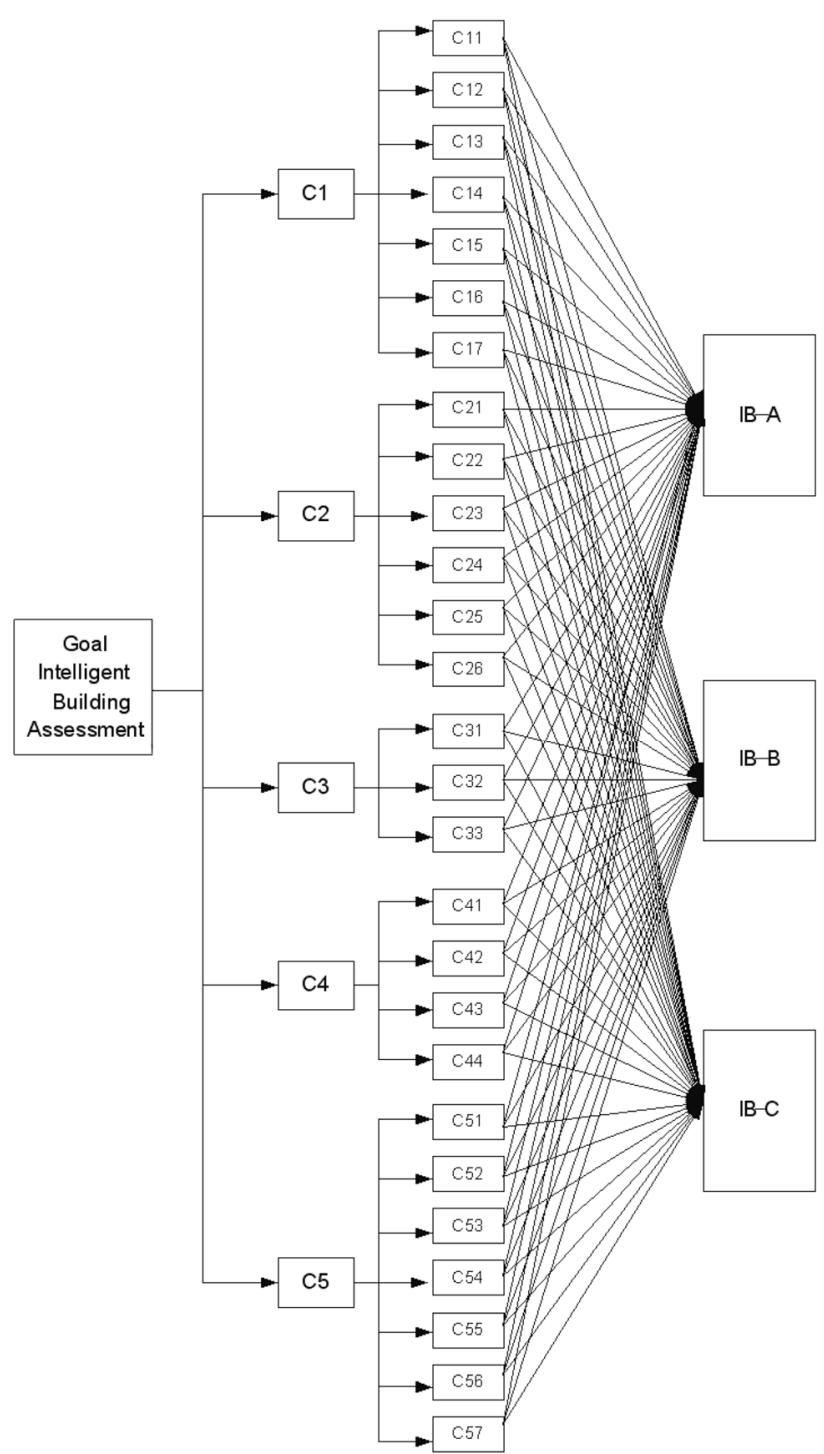

Fig. 2. The hierarchical structure for intelligent building assessment

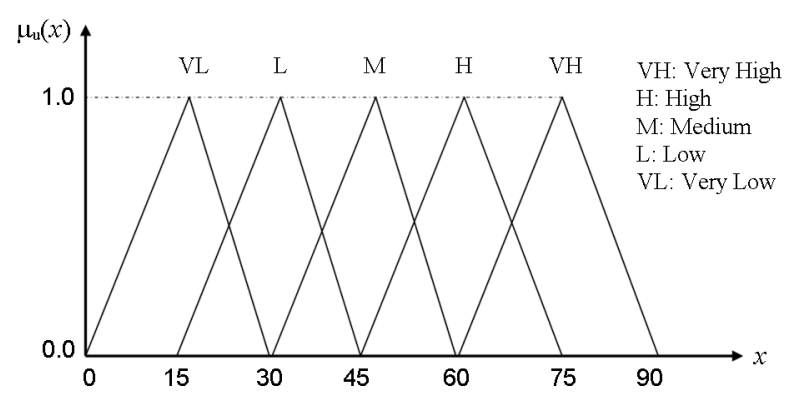

Fig. 3. The linguistic scale for utilities

The utilities of the all attributes are assigned by using a linguistic scale which is shown in Fig. 3 . The best and worst utilities are determined by using this linguistic scale. The scaling factors $k_{i}$, and utilities are obtained as fuzzy numbers from this scale.

Three types of decision maker are defined in the literature. Risk neutral means a situation in which a decision maker effectively ignores risk in making investment 
decisions. Given two investments with different levels of riskiness, a risk neutral decision maker considers only the expected return from each investment in intelligent buildings. As such, being risk neutral differs significantly from both risk averse and risk taker. Fig. 4 illustrates the membership function based utility curves of risk averse, risk neutral and risk taker decision makers. In our case, the decision makers who are composed of two professors from Civil Engineering Department, one professor from Mechatronics Engineering Department, and two top managers of construction sector, are risk neutral since the market conditions in Turkey are stable and present neither the chance gaining huge amount of money nor loosing it in a short time period.

The two types of questions to obtain the scaling factors are asked: "What probability $\tilde{P}$ of all attribute outcomes at their best levels $\left(\mathrm{C} 11^{*}, \mathrm{C} 12^{*}, \ldots, \mathrm{C} 15^{*}, \mathrm{C} 16^{*}, \ldots\right.$, $\left.\mathrm{C} 56^{*}, \mathrm{C} 7^{*}\right)$ versus probability $(1-\tilde{P})$ of all attribute outcomes at their worst levels $\left(\mathrm{C} 11^{0}, \mathrm{C} 12^{0}, \ldots, \mathrm{C} 15^{0}, \mathrm{C} 16^{0}, \ldots\right.$, $\mathrm{C} 56^{\circ}, \mathrm{C} 57^{\circ}$ ) would be as desirable as "Office automation" at its best level and all other attributes at their worst levels $\left(\mathrm{C} 11^{0}, \mathrm{C} 12^{0}, \ldots, \mathrm{C} 15^{*}, \mathrm{C} 16^{0}, \ldots, \mathrm{C} 56^{0}, \mathrm{C} 57^{0}\right) "$ ? The compromised answer from the decision makers was around 0.02 . Hence $\tilde{k}_{1}=(0.01,0.02,0.03)$. The next step is to ask the second question: "What office automation level, given functionality level at its worst, $\mathrm{C} 11^{0}$, (i.e. VL) would be as desirable as what functionality level, given the office automation level at its worst, $\mathrm{C} 15^{0}$, (ie. VL)"? The compromised answers from the decision makers were as follows: $\tilde{x}_{1}^{\prime}=$ Aproximately $50=(50,55,60)$ for office automation and $\tilde{x}_{2}^{\prime}=$ Aproximately $85=(80,85,90)$ for functionality.

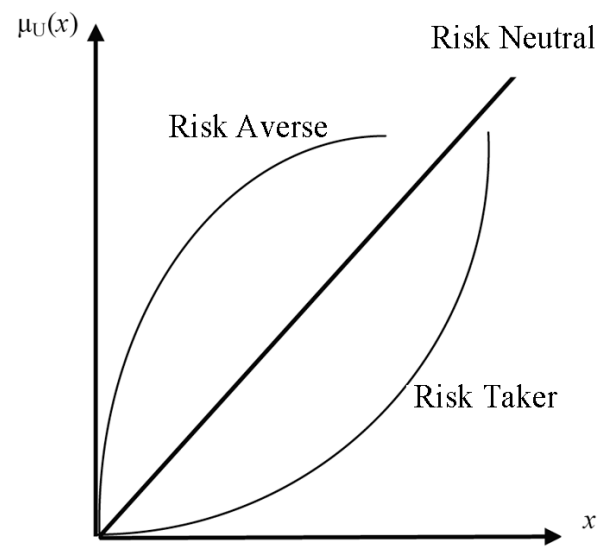

Fig. 4. Utility curves of various decision makers

Table 2. The local and global weights \& ranks of attributes for intelligent building assessment

\begin{tabular}{|c|c|c|c|c|c|}
\hline \multirow[b]{2}{*}{ Main Attributes } & \multirow[b]{2}{*}{ Sub-Attributes } & \multicolumn{2}{|c|}{ Local } & \multicolumn{2}{|c|}{ Global } \\
\hline & & Weight & Rank & Weight & Rank \\
\hline \multirow{7}{*}{$\begin{array}{l}\text { Engineering }(\mathrm{C} 1) \\
\qquad(0.368)\end{array}$} & Functionality (C11) & 0.327 & 2 & 0.12 & 2 \\
\hline & Safety and structure (C12) & 0.042 & 6 & 0.015 & 20 \\
\hline & Working efficiency (C13) & 0.107 & 3 & 0.039 & 8 \\
\hline & Responsiveness (C14) & 0.067 & 5 & 0.025 & 16 \\
\hline & Office automation (C15) & 0.347 & 1 & 0.128 & 1 \\
\hline & Power supply (C16) & 0.025 & 7 & 0.009 & 25 \\
\hline & System integration (C17) & 0.085 & 4 & 0.031 & 11 \\
\hline \multirow{6}{*}{$\begin{array}{l}\text { Environmental }(\mathrm{C} 2) \\
\qquad(0.136)\end{array}$} & Energy consumption (C21) & 0.074 & 6 & 0.01 & 24 \\
\hline & Water and Water Conservation (C22) & 0.078 & 5 & 0.011 & 23 \\
\hline & Materials used, Durability and Waste (C23) & 0.345 & 1 & 0.047 & 7 \\
\hline & Land use and Site selection (C24) & 0.276 & 2 & 0.037 & 9 \\
\hline & Greenhouse Gas Emissions (Pollution) (C25) & 0.103 & 4 & 0.014 & 21 \\
\hline & Indoor Environmental Quality (C26) & 0.124 & 3 & 0.017 & 19 \\
\hline \multirow{3}{*}{$\begin{array}{l}\text { Economical }(\mathrm{C} 3) \\
\qquad(0.041)\end{array}$} & Economic performance and affordability (C31) & 0.143 & 3 & 0.006 & 27 \\
\hline & Initial costs, operating and maintenance costs (C32) & 0.179 & 2 & 0.007 & 26 \\
\hline & Life cycle costing (C33) & 0.678 & 1 & 0.028 & 14 \\
\hline \multirow{4}{*}{$\begin{array}{l}\text { Socio-Cultural }(\mathrm{C} 4) \\
\qquad(0.106)\end{array}$} & Functionality, Usability and Aesthetic aspects (C41) & 0.126 & 4 & 0.013 & 22 \\
\hline & Human comfort (C42) & 0.337 & 1 & 0.036 & 10 \\
\hline & Health and sanitation $(\mathrm{C} 43)$ & 0.273 & 2 & 0.029 & 13 \\
\hline & $\begin{array}{l}\text { Architectural considerations - cultural heritage integration } \\
\text { and the compatibility with local heritage value }(\mathrm{C} 44)\end{array}$ & 0.264 & 3 & 0.028 & 15 \\
\hline \multirow{7}{*}{$\begin{array}{l}\text { Technological (C5) } \\
\qquad(0.349)\end{array}$} & Work efficiency (C51) & 0.150 & 3 & 0.052 & 5 \\
\hline & Use of high-tech system (C52) & 0.321 & 1 & 0.112 & 3 \\
\hline & Use of advanced artificial intelligence (C53) & 0.144 & 4 & 0.05 & 6 \\
\hline & Telecom and data system- Connectibility (C54) & 0.172 & 2 & 0.06 & 4 \\
\hline & Security monitoring and access control system (C55) & 0.088 & 5 & 0.031 & 12 \\
\hline & Addressable fire detection and alarm system (C56) & 0.056 & 7 & 0.02 & 18 \\
\hline & Digital addressable lighting control system (C57) & 0.069 & 6 & 0.024 & 17 \\
\hline
\end{tabular}


These fuzzy values are defuzzified by using Liou and Wang's (1992) integral value and their membership values are obtained from the linguistic scale in Fig. 3. Then the scaling factor for functionality is calculated as below:

$$
\tilde{k}_{i} U_{i}\left(\tilde{x}_{i}^{\prime}\right)=\tilde{k}_{2} U_{2}\left(\tilde{x}_{2}^{\prime}\right) \text {; }
$$

$(0.01,0.02,0.03) \otimes U_{1}(50,55,60)=\tilde{k}_{2} \otimes U_{2}(80,85,90) ;$

$(0.01,0.02,0.03) \times 0.67=\tilde{k}_{2} \times 0.33$;

$\tilde{k}_{2}=(0.02,0.04,0.06)$.

The fuzzy scaling factors for the other attributes are obtained by the same way and they are shown in Table 3.

Since $\sum_{i=1}^{n} \tilde{k}_{i} \neq(1,1,1)$, the fuzzy multiplicative model is suitable for intelligent assessment of buildings.

The compromised outcomes from the decision makers for building alternatives and their utilities are obtained as shown in Table 4.

Then the fuzzy scaling constant $\tilde{K}$, is determined as $\tilde{K}=(-0.0003,-0.0002,-0.0001)$. The fuzzy utility values for intelligent building alternatives are calculated as given in Table 5 .

The graphical representations of membership functions for building alternatives are illustrated in Fig. 5.
Table 3. The fuzzy scaling factor values and ranking of the sub-attributes

\begin{tabular}{|c|c|c|c|}
\hline $\begin{array}{c}\text { Sub- } \\
\text { Attributes }\end{array}$ & Rank & $\begin{array}{l}\text { Utility } \\
\text { Range }\end{array}$ & $\tilde{k}_{i}$ \\
\hline $\mathrm{C} 15$ & 1 & $\mathrm{VL}-\mathrm{VH}$ & $(0.01,0.02,0.03)$ \\
\hline C11 & 2 & VL-VH & $(0.02,0.04,0.06)$ \\
\hline $\mathrm{C} 52$ & 3 & VL-VH & $(0.03,0.06,0.09)$ \\
\hline C54 & 4 & VL-VH & $(0.06,0.12,0.18)$ \\
\hline C51 & 5 & VL-VH & $(0.09,0.18,0.27)$ \\
\hline $\mathrm{C} 53$ & 6 & VL-VH & $(0.06,0.12,0.18)$ \\
\hline $\mathrm{C} 23$ & 7 & VH-VL & $(0.18,0.36,0.54)$ \\
\hline $\mathrm{C} 13$ & 8 & VL-VH & $(0.06,0.12,0.18)$ \\
\hline $\mathrm{C} 24$ & 9 & VL-VH & $(0.02,0.04,0.06)$ \\
\hline $\mathrm{C} 42$ & 10 & VL-VH & $(0.0067,0.013,0.02)$ \\
\hline $\mathrm{C} 17$ & 11 & VL-VH & $(0.0034,0.0065,0.01)$ \\
\hline $\mathrm{C} 55$ & 12 & VL-VH & $(0.002,0.0033,0.01)$ \\
\hline $\mathrm{C} 43$ & 13 & VL-VH & $(0.001,0.0017,0.01)$ \\
\hline $\mathrm{C} 33$ & 14 & VH-VL & $(0.001,0.0017,0.01)$ \\
\hline $\mathrm{C} 44$ & 15 & VL-VH & $(0.0015,0.00255,0.015)$ \\
\hline C14 & 16 & VL-VH & $(0.0015,0.00255,0.015)$ \\
\hline $\mathrm{C} 57$ & 17 & VL-VH & $(0.003,0.0051,0.03)$ \\
\hline C56 & 18 & VL-VH & $(0.006,0.0102,0.06)$ \\
\hline $\mathrm{C} 26$ & 19 & VL-VH & $(0.012,0.0204,0.12)$ \\
\hline $\mathrm{C} 12$ & 20 & VL-VH & $(0.024,0.0408,0.24)$ \\
\hline $\mathrm{C} 25$ & 21 & VL-VH & $(0.048,0.0816,0.48)$ \\
\hline $\mathrm{C} 41$ & 22 & VL-VH & $(0.024,0.0408,0.24)$ \\
\hline $\mathrm{C} 22$ & 23 & VL-VH & $(0.012,0.0204,0.12)$ \\
\hline $\mathrm{C} 21$ & 24 & VH-VL & $(0.036,0.0612,0.36)$ \\
\hline $\mathrm{C} 16$ & 25 & VL-VH & $(0.036,0.0612,0.36)$ \\
\hline $\mathrm{C} 32$ & 26 & VH-VL & $(0.036,0.0612,0.36)$ \\
\hline $\mathrm{C} 31$ & 27 & VL-VH & $(0.036,0.0612,0.36)$ \\
\hline & & \multicolumn{2}{|c|}{$\sum_{i=1}^{n} \tilde{k}_{i}=(0.820,1.555,4.410)$} \\
\hline
\end{tabular}

Table 4. The outcomes and utilities for building alternatives

\begin{tabular}{|c|c|c|c|c|c|c|}
\hline & \multicolumn{2}{|l|}{ IB-A } & \multicolumn{2}{|l|}{ IB-B } & \multicolumn{2}{|c|}{ IB-C } \\
\hline & $\tilde{x}_{i}$ & $U_{i}\left(\tilde{x}_{i}\right)$ & $\tilde{x}_{i}$ & $U_{i}\left(\tilde{x}_{i}\right)$ & $\tilde{x}_{i}$ & $U_{i}\left(\tilde{x}_{i}\right)$ \\
\hline $\mathrm{C} 15$ & Approximately 55 & 0.667 & Approximately 60 & 1.000 & Approximately 65 & 0.667 \\
\hline C11 & Approximately 60 & 1.000 & Approximately 60 & 1.000 & Approximately 70 & 0.333 \\
\hline $\mathrm{C52}$ & Approximately 65 & 0.667 & Approximately 65 & 0.667 & Approximately 65 & 0.667 \\
\hline C54 & Approximately 65 & 0.667 & Approximately 60 & 1.000 & Approximately 70 & 0.333 \\
\hline $\mathrm{C51}$ & Approximately 50 & 0.333 & Approximately 60 & 1.000 & Approximately 65 & 0.667 \\
\hline $\mathrm{C} 53$ & Approximately 25 & 0.667 & Approximately 60 & 1.000 & Approximately 70 & 0.333 \\
\hline $\mathrm{C} 23$ & Approximately 60 & 1.000 & Approximately 60 & 1.000 & Approximately 70 & 0.333 \\
\hline C13 & Approximately 45 & 1.000 & Approximately 50 & 0.333 & Approximately 70 & 0.333 \\
\hline $\mathrm{C} 24$ & Approximately 70 & 0.333 & Approximately 70 & 0.333 & Approximately 70 & 0.333 \\
\hline $\mathrm{C} 42$ & Approximately 50 & 0.333 & Approximately 60 & 1.000 & Approximately 70 & 0.333 \\
\hline $\mathrm{C} 17$ & Approximately 54 & 0.600 & Approximately 55 & 0.667 & Approximately 66 & 0.400 \\
\hline $\mathrm{C55}$ & Approximately 70 & 0.333 & Approximately 74 & 0.067 & Approximately 75 & 1.000 \\
\hline $\mathrm{C} 43$ & Approximately 73 & 0.133 & Approximately 75 & 1.000 & Approximately 75 & 1.000 \\
\hline $\mathrm{C} 33$ & Approximately 66 & 0.600 & Approximately 70 & 0.333 & Approximately 77 & 0.867 \\
\hline $\mathrm{C} 44$ & Approximately 45 & 1.000 & Approximately 71 & 0.733 & Approximately 73 & 0.867 \\
\hline C14 & Approximately 55 & 0.667 & Approximately 60 & 1.000 & Approximately 65 & 0.667 \\
\hline C57 & Approximately 74 & 0.067 & Approximately 70 & 0.333 & Approximately 70 & 0.333 \\
\hline $\mathrm{C56}$ & Approximately 73 & 0.133 & Approximately 70 & 0.333 & Approximately 74 & 0.933 \\
\hline $\mathrm{C} 26$ & Approximately 80 & 0.667 & Approximately 75 & 1.000 & Approximately 82 & 0.533 \\
\hline $\mathrm{C} 12$ & Approximately 75 & 1.000 & Approximately 80 & 0.667 & Approximately 78 & 0.800 \\
\hline $\mathrm{C} 25$ & Approximately 83 & 0.467 & Approximately 80 & 0.667 & Approximately 80 & 0.667 \\
\hline $\mathrm{C} 41$ & Approximately 63 & 0.800 & Approximately 60 & 1.000 & Approximately 72 & 0.800 \\
\hline $\mathrm{C} 22$ & Approximately 50 & 0.333 & Approximately 50 & 0.333 & Approximately 50 & 0.333 \\
\hline $\mathrm{C} 21$ & Approximately 67 & 0.533 & Approximately 65 & 0.667 & Approximately 63 & 0.800 \\
\hline C16 & Approximately 87 & 0.200 & Approximately 85 & 0.333 & Approximately 88 & 0.133 \\
\hline C32 & Approximately 45 & 1.000 & Approximately 45 & 1.000 & Approximately 50 & 0.333 \\
\hline C31 & Approximately 45 & 1.000 & Approximately 43 & 0.867 & Approximately 47 & 0.867 \\
\hline
\end{tabular}


Table 5. Fuzzy utility values for building alternatives

\begin{tabular}{c|c}
\hline & $U_{i}\left(\tilde{x}_{i}\right)$ \\
\hline IB-A & $(0.588,1.122,3.028)$ \\
IB-B & $(0.674,1.288,3.408)$ \\
IB-C & $(0.394,0.736,2.364)$ \\
\hline
\end{tabular}

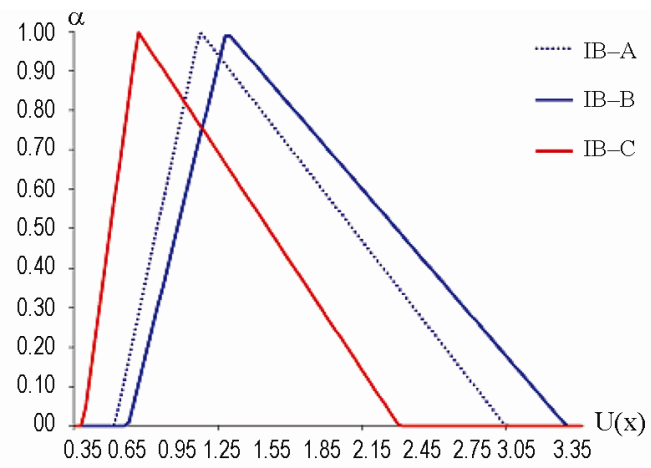

Fig. 5. The membership functions of intelligent building alternatives

To determine the most appropriate building alternative, it is necessary to compare membership functions for utility presented in Table 5 . For this aim, a comparison method which was proposed by Tran and Duckstein (2002) is used. The method is based on the comparison of distances from fuzzy numbers (FNs) to some predetermined targets: the crisp maximum (Max) and the crisp minimum (Min). The idea is that an FN is ranked first if its distance to the crisp maximum $\left(D_{\max }\right)$ is the smallest, but its distance to the crisp minimum $\left(D_{\min }\right)$ is the greatest. If only one of these conditions is satisfied, a FNs might be outranked the others depending upon context of the problem (for example, the attitude of the decisionmaker in a decision situation). The Max and Min are chosen as follows (Tran, Duckstein 2002):

$$
\begin{aligned}
& \operatorname{Max}(I) \geq \sup \left(\bigcup_{i=1}^{I} s\left(\tilde{A}_{i}\right)\right) ; \\
& \operatorname{Min}(I) \leq \inf \left(\bigcup_{i=1}^{I} s\left(\tilde{A}_{i}\right)\right),
\end{aligned}
$$

where $s\left(A_{i}\right)$ is the support of FNs $\tilde{A}_{\mathrm{i}}$ for $i=1, \ldots$,I. Then $D_{\max }$ and $D_{\min }$ of fuzzy number $\tilde{A}\left(a_{1}, a_{2}, a_{3}\right)$ can be computed as follows:

$$
\begin{aligned}
& D^{2}(\tilde{A}, M)= \\
& \left\{\begin{array}{l}
\left(a_{2}-M\right)^{2}+\frac{1}{2}\left(a_{2}-M\right)\left[\left(a_{3}+a_{1}\right)-2 M\right]+ \\
\frac{1}{9}\left[\left(a_{3}-a_{2}\right)^{2}+\left(a_{2}-a_{1}\right)^{2}\right]-\frac{1}{9}\left[\left(a_{2}-a_{1}\right)\left(a_{3}-a_{2}\right)\right],
\end{array}\right.
\end{aligned}
$$

where $M$ is either Max or Min.
Hence:

$$
D_{\max }=\sqrt{D^{2}(\tilde{A}, \operatorname{Max})} \text { and } D_{\min }=\sqrt{D^{2}(\tilde{A}, \operatorname{Min})} .
$$

The results of these comparisons are shown in Table 6. According to Table 6, IB-B is determined as the most appropriate alternative as an intelligent building.

Table 6. The comparison results for intelligent building alternatives

\begin{tabular}{c|c|c|c|c|c|c}
\hline & $\mathrm{a}_{1}$ & $\mathrm{a}_{2}$ & $\mathrm{a}_{3}$ & $\mathrm{D}_{\max }$ & $\mathrm{D}_{\min }$ & Rank \\
\hline IB-A & 0.5885 & 1.1223 & 3.0279 & 3.034 & 1.372 & 2 \\
IB-B & 0.6738 & 1.2876 & 3.4081 & 2.792 & 1.633 & 1 \\
IB-C & 0.3939 & 0.7364 & 2.3641 & 3.578 & 0.837 & 3 \\
\hline
\end{tabular}

\section{Conclusions}

An intelligent building is responsible to provide embracing sustainability, energy efficiency, smart technologies and techniques allowing more and better to be delivered for less. It provides a sustainable, responsive, effective and supportive environment within which individuals and organizations can achieve their objectives.

Multiple attribute utility analysis is targeted in solving problems of trading off the achievement of some objectives against other objectives to obtain the maximum overall utility. Multiple attribute utility analysis is used to assess the decision-maker's preference structure and model it mathematically with a multiple attribute utility function. This multiple attribute utility function is then applied to help the decision maker reach an optimal decision.

Since the fuzzy set theory provides a mathematical formalism for vagueness and imprecision that is ever present in decision support systems in many areas, the fuzzy set theory is integrated with MAUT to increase its flexibility and sensitiveness in this paper. In the evaluation process, the fuzzy set theory brings many advantages on MAUT such as a possibility to evaluate immeasurable criteria and to take into consideration evaluation of human judgments. The fuzzy set theory also gives an advantage that is an ease definition of score for alternative and is a flexible scale for expert judgments.

A fuzzy multiple attribute utility model for intelligent building assessment has been proposed and it has been successfully applied for the assessment of building alternatives for a business center in İstanbul. The fuzzy results do not only include a point value for utility of building alternatives but also show all possible value with relevant degree of membership. It brings an advantage on sensitivities of results and they can be interpreted more deeply. As a result of evaluation process, the alternative IB-B is selected as the most suitable building with respect to intelligent level. The ranking of alternative is also determined as follows: $\{\mathrm{IB}-\mathrm{B}$; IB-A; IB-C $\}$.

For the further research the other multiattribute decision making tools such as AHP, VIKOR, and TOPSIS can be used for intelligent building assessment and the obtained results can be compared with the results of our fuzzy multiple attribute utility model. 


\section{References}

Abouelnaga, A. E.; Metwally, A.; Nagy, M. E.; Agamy, S. 2009. Optimum selection of an energy resource using fuzzy logic, Nuclear Engineering and Design 2399(12): 3062-3068.

http://dx.doi.org/10.1016/j.nucengdes.2009.09.002

ALwaer, H.; Clements-Croome, D. J. 2010. Key performance indicators (KPIs) and priority setting in using the multiattribute approach for assessing sustainable intelligent buildings, Building and Environment 45(4): 799-807. http://dx.doi.org/10.1016/j.buildenv.2009.08.019

Beliakov, G.; Warren, J. 2001. Appropriate choice of aggregation operators in fuzzy decision support systems, IEEE Transactions on Fuzzy Systems 9(6): 773-784. http://dx.doi.org/10.1109/91.971696

Butler, J.; Morrice, D. J.; Mullarkey, P. W. 2001. A multiple attribute utility theory approach to ranking and selection, Management Science 47(6): 800-816. http://dx.doi.org/10.1287/mnsc.47.6.800.9812

Canada, J. R.; Sullivian, W. G. 1988. Economic and multiattribute evaluation of advanced manufacturing systems. Prentice Hall, New Jersey. 480 p.

Chen, Z.; Clements-Croome, D.; Hong, J.; Li, H.; Xu, Q. 2006. A multicriteria lifespan energy efficiency approach to intelligent building assessment, Energy and Buildings 38(5): 393-409. http://dx.doi.org/10.1016/j.enbuild.2005.08.001

Cirtita, H.; Ilieş, L. 2009. Does structure influence performance in downstream supply chain?, Review of International Comparative Management 10(1): 106-112.

De Melo Brito, A. J.; De Almeida Filho, A. T.; De Almeida, A. T. 2010. Multi-criteria decision model for selecting repair contracts by applying utility theory and variable interdependent parameters, IMA Journal of Management Mathematics 21(4): 349-361.

http://dx.doi.org/10.1093/imaman/dpn014

Hong, J.; Chen, Z.; Li, H.; Xu, Q. 2006. An information visualization approach to intelligent building assessment, in Proc. of the $6^{\text {th }}$ International Conference for Enhanced Building Operations, Shenzhen, China, 6-9 November, 2006, Vol. VIII-6-4: ESL-IC-06-11-284.

Jiménez, A.; Mateos, A.; Rios-Insua, S. 2009. Missing consequences in multiattribute utility theory, Omega 37(2): 395-410. http://dx.doi.org/10.1016/j.omega.2007.04.003

Jiménez, A.; Rios-Insua, S.; Mateos, A. 2003. A decision support system for multiattribute utility evaluation based on imprecise assignments, Decision Support Systems 36(1): 65-79. http://dx.doi.org/10.1016/S0167-9236(02)00137-9

Kainuma, Y.; Tawara, N. 2006. A multiple attribute utility theory approach to lean and green supply chain management, International Journal of Production Economics 101(1): 99-108.

http://dx.doi.org/10.1016/j.ijpe.2005.05.010

Keeney, R. L.; Raiffa, H. 1976. Decisions with Multiple Objectives. Wiley, New York. 569 p.

Kolokotsa, D.; Sutherland, G.; Stavrakakis, G.; Karatassou, S.; Santamouris, M. 2007. A matrix tool for assessing the performance of intelligent buildings, Management of Environmental Quality: An International Journal 18(1): 3649. http://dx.doi.org/10.1108/14777830710717703

Liou, T. S.; Wang, M. J. J. 1992. Ranking fuzzy numbers with integral value, Fuzzy Sets and Systems 50(3): 247-255. http://dx.doi.org/10.1016/0165-0114(92)90223-Q
Malakooti, B. 1989. Ranking multiple criteria alternatives with half-space, convex, and non-convex dominating cones: quasi-concave and quasi-convex multiple attribute utility functions, Computers \& Operations Research 16(2): 117127. http://dx.doi.org/10.1016/0305-0548(89)90014-2

Malakooti, B.; Subramanian, S. 1999. Generalized polynomial decomposable multiple attribute utility functions for ranking and rating multiple criteria discrete alternatives, $A p$ plied Mathematics and Computation 106(1): 69-102. http://dx.doi.org/10.1016/S0096-3003(98)10113-3

Nishizaki, I.; Katagiri, H.; Hayashida, T. 2010. Sensitivity analysis incorporating fuzzy evaluation for scaling constants of multiattribute utility functions, Central European Journal of Operations Research 18(3): 383-396. http://dx.doi.org/10.1007/s10100-009-0115-1

SAVE, 2010. Available Intelligent Buildings Assessment methodology [accessed 10 January 2011]. Available from Internet: http://www.ibuilding.gr

Sohn, K. Y.; Yang, J. W.; Kang, C. S. 2001. Assimilation of public opinions in nuclear decision-making using risk perception, Annals of Nuclear Energy 28(6): 553-563. http://dx.doi.org/10.1016/S0306-4549(00)00076-1

Streicher-Porte, M.; Marthaler, C.; Böni, H.; Schluep, M.; Camacho, A.; Hilty, L. M. 2009. One laptop per child, local refurbishment or overseas donations? Sustainability assessment of computer supply scenarios for schools in Colombia, Journal of Environmental Management 90(11): 3498-3511. http://dx.doi.org/10.1016/j.jenvman.2009.06.002

Tran, L.; Duckstein, L. 2002. Comparison of fuzzy numbers using a fuzzy distance measure, Fuzzy Sets and Systems Fuzzy Intervals 130(3): 331-341.

Tupenaite, L.; Zavadskas, E. K.; Kaklauskas, A.; Turskis, Z.; Seniut, M. 2010. Multiple criteria assessment of alternatives for built and human environment renovation, Journal of Civil Engineering and Management 16(2): 257266. http://dx.doi.org/10.3846/jcem.2010.30

Wang, M.-L.; Kuo, T.-C.; Liu, J.-W. 2009. Identifying target green $3 \mathrm{C}$ customers in Taiwan using multiattribute utility theory, Expert Systems with Applications 36(10): 1256212569. http://dx.doi.org/10.1016/j.eswa.2009.05.033

Wong, J. K. W.; Li, H. 2008. Application of the analytic hierarchy process (AHP) in multi-criteria analysis of the selection of intelligent building systems, Building and Environment 43(1): 108-125.

http://dx.doi.org/10.1016/j.buildenv.2006.11.019

Wong, J. K. W.; Li, H.; Wang, S. W. 2005. Intelligent building research: a review, Automation in Construction 14(1): 143-159. http://dx.doi.org/10.1016/j.autcon.2004.06.001

$\mathrm{Xu}, \mathrm{N}$.; Huang, S. H. 2006. Multiple attributes utility analysis in setup plan evaluation, Journal of Manufacturing Science and Engineering 128(1): 220-227. http://dx.doi.org/10.1115/1.2117407

Yang, Z. L.; Bonsall, S.; Wang, J. 2009. Use of hybrid multiple uncertain attribute decision making techniques in safety management, Expert Systems with Applications 36(2): 1569-1586. http://dx.doi.org/10.1016/j.eswa.2007.11.054

Zadeh, L. A. 1965. Fuzzy sets, Information and Control 8(3): 338-353. http://dx.doi.org/10.1016/S0019-9958(65)90241-X

Zhang, H. 2008. Multi-objective simulation-optimization for earthmoving operations, Automation in Construction 18(1): 79-86.

http://dx.doi.org/10.1016/j.autcon.2008.05.002 
Zhang, H.; Xing, F. 2010. Fuzzy-multi-objective particle swarm optimization for time-cost-quality tradeoff in construction, Automation in Construction 19(8): 1067-1075. http://dx.doi.org/10.1016/j.autcon.2010.07.014
Zimmermann, H. J. 1991. Fuzzy Set Theory and Its Applications. 2nd ed. Boston: Kluwer. 399 p.

Cengiz KAHRAMAN. Prof. Kahraman's BSc, MSc, and PhD degrees are from Istanbul Technical University and on Industrial Engineering. His main research areas are engineering economics, quality management and control, statistical decision making, and fuzzy sets applications. He published international journal papers over one hundred and four edited books from Springer. He guest-edited many special issues of international journals. He is presently the head of Industrial Engineering department of Istanbul Technical University.

İhsan KAYA. Assoc. Prof. Kaya received the BS and MSc degrees in Industrial Engineering from Selçuk University. He also received $\mathrm{PhD}$ degree from Istanbul Technical University on Industrial Engineering. He is currently an Assoc. Prof. Dr at Yıldız Technical University Department of Industrial Engineering. His main research areas are process capability analysis, quality management and control, statistical and multicriteria decision making, and fuzzy sets applications. 